Page, Amy Dellinger. (2008) 'Judging Women and Defining Crime: Police Officers' Attitudes Toward Women and Rape." Sociological Spectrum 28 (4), 389-411. Published by Taylor \& Francis (ISSN: 1521-0707) DOI: 10.1080/02732170802053621 July 2008

\title{
Judging Women and Defining Crime: Police Officers' Attitudes Toward Women and Rape
}

\author{
Amy Dellinger Page
}

\begin{abstract}
Research demonstrates a positive relationship between public attitudes toward women and rape myth acceptance. Little is known about whether this relationship also exists within police culture. The current study assesses the relationship between police officers' attitudes toward women and their attitudes toward rape. The effect of educational attainment on these attitudes is also assessed. A survey was administered to 891 police officers from two states in the southeastern United States. There was a significant difference on measures of modern sexism and the acceptance of rape myths with varying levels of educational attainment.
\end{abstract}

\footnotetext{
ARTICLE

Differential expectations about acceptable behavior for males and females influence our thoughts and behaviors as well as our expression and evaluation of gender and sexuality. Men and women are socialized to hold gendered expectations about sexuality and these differential expectations inform attitudes toward rape. Police officers are invariably influenced by their socialization, as is anyone raised within a particular society. To address this issue, some police agencies have attempted to alter their policies and training concerning rape victims to resocialize officers' views following rape law reforms. Studies in Britain and New Zealand found that, although improvements had been made within police culture resulting in greater satisfaction among rape victims who reported their crime to police, a sizable minority of dissatisfied victims remained (Temkin 1997; Jordan 2001). Given the amount of discretion afforded to police officers and that police officers are often a rape victim's first contact with the criminal
} 
justice system, it is important to assess their attitudes toward women and rape. Doing so would not only contribute to the literature in this area, but could provide the basis for changes in police training.

\section{ATTITUDES TOWARD WOMEN}

Insofar as rape is gendered action, it is difficult, if not impossible, to discuss attitudes toward rape without discussing attitudes about gender, including one's own gender socialization. Gender and gendered relationships are constructed in ways that reflect the social organization of life and are rooted in a culture's history, economy, and political and social ideologies (Wade and Tavris 1998). Decisions about what attributes and behaviors are considered "masculine" and "feminine" are established by the dominant group(s) in a society (Fortier 1975). Within a patriarchal culture, like that of the contemporary United States, males in the aggregate dominate females. Gendered constructions, which are characteristically discussed in polar opposite terminology, serve male interests. For instance, appropriate masculine characteristics are intelligence, aggressiveness and virility, while valued feminine characteristics reflect subjugation, docility, passivity and naiveté (Johnson 1997).

Gender is a social institution, one that organizes and stratifies many aspects of day-to-day life (Bem 1981; Lorber 2003). Gender norms and attributions influence allowable emotions and even personality characteristics. As gender typically (but not always) corresponds with one's biological sex, differences between men and women and the ways in which they experience life are seen as natural rather than socially constructed (Beall 1993; Lorber 2003).

West and Zimmerman (1987) note that "doing gender" is part of one's daily routine and cuts across all situations and encounters. We perform our gender as a way to convey our sex to others and this reinforces the idea of difference between the sexes. This difference in gender performance contributes to the formation and perpetuation of gender stereotypes. Adherence to gender role stereotypes results in sexist attitudes toward women. These attitudes may be blatantly expressed or more subversive in nature.

Women's expression of gender and sexuality are relevant to how rape victims are perceived by the criminal justice system and the general public. For instance, women who adhere closely to their gender stereotype are seen as more credible than those who deviate from the accepted expectations. A woman's demeanor, sexual expression, and sexual history become particularly salient when allegations of sexual 
violence are levied against men. However, these deliberate and obvious forms of sexism are "old-fashioned," and many now recognize that these attitudes are not publicly accepted (Swim et al. 1995).

Benokraitis and Feagin (1986) argue that negative attitudes toward women have become increasingly covert and that sexism now takes more subtle forms. One example of the subtle nature of contemporary sexism is the denial that women continue to be discriminated against, despite lower salary earnings (Stroh et al. 1992) and the persistence of unequal distribution of household labor, even for women who hold professional jobs (Biernat and Wortman 1991).

In order to test the overt forms of old-fashioned sexism and the more covert forms of modern sexism, Swim, Aikin, Hall, and Hunter (1995) conducted phone surveys using a closed-ended questionnaire with female and male introductory psychology students. The scales were adapted from McConahay's (1986) Old-Fashioned and Modern Racism Scales, to apply specifically to sexism. The researchers found that men scored significantly higher on measures of old-fashioned and modern sexism than women, indicating that they held more sexist and less egalitarian attitudes toward women.

\section{ATTITUDES TOWARD RAPE}

Burt (1980) was the first to empirically study "rape myths," which refer to the stereotypical and empirically incorrect beliefs that an individual holds concerning rape, rapists, and the victims of rape. Some examples of rape myths include: "only bad girls get raped," "women ask for it," and "women 'cry rape' only when they've been jilted or have something to cover up."

Rape myths may provide a justification (e.g., she seemed to like it) or an excuse (e.g., that was bad, but l'm not [wholly] responsible) for the (male) rapist's behavior) (Scott and Lyman 1968). That is, responsibility is either displaced from perpetrators on the idea that they surpassed the level of "controllable" sexual stimulation and could no longer be held accountable for their actions (Bart 1979) or female victims and potential victims are cast as the responsible party. They are instructed to be aware of male propensities and take action (or remain passive) to avoid rape. Women are told not to dress provocatively so as not to arouse the presumed uncontrollable sexual urges in men. They are also instructed not to go out at night alone. Rather, they should keep protection (a man) with them at all times if possible. All of these messages warn of the looming possibility of rape, which restricts the movement of women and to a certain extent 
dictates how, when, and where women travel and congregate (Stanko 1997).

For many, rape myths are a commonsense approach to understanding and explaining the crime of rape. Yet, myths, like most stereotypes, often represent a stark contrast to reality (Doherty and Anderson 1998). For instance, a common rape myth is that a victim will have physical injuries following the rape because one cannot be raped against her=his will. However, Bonney (1985) found that $44 \%$ of rape victims have no physical injuries. In many cases, rape is accomplished through verbal and psychological coercion rather than physical force. This figure is likely underestimated, as the sample included only known victims of rape.

Another dominant myth is that sexually active women are more likely to lie about being sexually attacked than are those deemed "chaste." Although women are free to enjoy more sexual partners than in recent history, they are held accountable for this behavior if they are the victims of sexual violence (Schwartz and Rutter 1998). Notably, victims of robbery or car theft are not held accountable for how many times they have been victims of that crime. Even if some blame is attributed (e.g., he shouldn't have been carrying that much cash), the social implications of the blame are not equivalent to those experienced by rape victims.

The close monitoring, control, and access of women's sexuality is fostered by a patriarchal society where men dominate women in many, if not all, spheres of economic, social, and political life (Johnson 1997; Kimmel 2000). By advising women not to walk alone at night, women are made to feel dependent on men (or the masculine state) for their safety. Society can thereby restrict women's behavior (Wesely and Gaarder 2004), making them responsible for being raped if they were alone. Another common myth is that women often lie about being raped. However, Ward (1995) reported that just one to four percent of rape myths constitute false reports, ${ }^{1}$ a figure not significantly different from false reports of other crimes.

Several studies have been conducted to determine the public's level of endorsement of various rape myths. Field (1978) surveyed individuals regarding their attitudes toward rape and found that male respondents attributed greater responsibility to the woman to prevent a rape and believed that victims precipitate rape through provocative dress or behavior. Male respondents, however, also tended to believe that women should not resist during a rape and that the punishment for rape should be severe. Unlike their female counterparts, male respondents generally did not express a belief that rapists are 
mentally ill or that they are motivated by a need to have power over women. More positive attitudes toward women, expressed by the respondents, correlated with the belief that the rapist's motivation is not sex, but rather an exercise of power and domination over the victim.

Burt (1980) surveyed individuals in Minnesota and found strong endorsement of rape myths across the sample. Over half of Burt's sample endorsed rape myths like "A woman who goes to the home or apartment of a man on the first date implies she is willing to have sex" and "In the majority of rapes, the victim was promiscuous or had a bad reputation." Likewise, more than half of the respondents believed that at least $50 \%$ of rape complaints were by women who intended to get back at men they were angry with or because the victims were trying to cover up an illegitimate pregnancy. She found that the acceptance of rape myths was highly correlated with other attitudes such as sex role stereotyping (R2 1/4 0.309) and adversarial sexual beliefs (R2 $1 / 40.292)$, demonstrating the relationship between rape myths and sexist attitudes.

Mayerson and Taylor (1987) also examined the influence of sex role stereotyping on the acceptance of rape myths. Female undergraduates were assigned to one of three conditions involving a story that varied with respect to the degree of consent and arousal in a sexual situation. Mayerson and Taylor found that subjects with a high score on sex role stereotyping also had a high score on the acceptance of rape myths, regardless of the level of consent or arousal of the woman in the story (Mayerson and Taylor 1987).

The acceptance and perpetuation of rape myths results in the construction of "real rapes" and "real victims" by the public (including victims) and the criminal justice system (DuMont et al. 2003; ClayWarner and Burt 2005). "Real rapes" are those identified by the criminal justice system as aggravated rapes. Aggravated rapes are those characterized by the stereotypical rape in which a stranger, say, jumps from the bushes and physically and sexually attacks his victim. Because the perpetrator in these situations is typically a stranger a weapon is commonly employed, as is the use of physical violence in order to subdue the victim. Aggravated rapes are not usually held to the same level of scrutiny by criminal justice personnel, as are acquaintance assaults. The crime and the victim fit people's perceptions of what constitutes a "real rape" involving a "real victim." The victim is seen as having less of a reason to lie about the attack because she does not know the attacker. Additionally, since physical violence often accompanies the attack, there is more physical proof that a rape occurred. Because of these factors, the victim often 
reports the crime to police within a shorter period of time than does the typical victim of acquaintance rape (Spohn and Horney 1993; Spears and Spohn 1996).

Simple rape cases, however, do not involve these aggravating circumstances (Spohn and Horney 1996) and are not necessarily viewed as "real rapes." Typically, simple sexual assault cases are those involving acquaintances. Given the existence of a prior or current relationship, physical force is not necessarily needed to ensure the sexual assault. Rather, an offender may rely on verbal threats, intimidation, and=or coercion to accomplish the assault. These factorsamounting to a lack of tangible evidence-make charging and prosecuting simple sexual assault cases very difficult. Furthermore, the ambiguity of the characteristics of the assault promotes stereotypic analysis by individuals and criminal justice personnel. Police, prosecutors, juries, and judges fear charging and=or convicting an innocent person. They see more reason for the victim to lie about the attack when she knows her assailant than when he is a stranger (Spohn and Horney 1993). In addition, the victim in these cases is likely to take longer to report the crime to police for the same reasons that make the case ambiguous to criminal justice personnel (Cairney 1995). This lapse in time contributes to the negative assessment of the alleged assault. Since approximately $85 \%$ of victims are sexually assaulted by someone they know and prior relationship spurs the aforementioned biases and complications, it is no wonder that rape reports are no higher than they are (Spohn and Horney 1993; Cairney 1995).

\section{Police Culture as Masculinity}

Men in American society are socialized to espouse "macho" beliefs and behavior. Connell $(1987,1995,2002)$ refers to this as "hegemonic masculinity," an idealized form of masculinity, emphasizing dominance, aggression, heterosexuality, and a lack of emotion. Hegemonic masculinity promotes but does not determine behavior that supports the traditional gender order. Rather, it shapes one's sense of reality and is modified to fit different situations (Messerschmidt 2000). In other words, hegemonic masculinity acts as a script for how men should behave and=or think in various situations.

Socialization in adulthood takes the form of learning and adapting our worldview to what is deemed appropriate in various social settings, including occupational settings. Holdaway (1983) discusses police culture as an informal structure of norms and values that operate within the more rigid hierarchy of the police organization. As recruits, police officers not only learn the skills and policies needed for police work, they also learn the cultural norms associated 
with law enforcement.

Fielding (1994, p. 47) states that police culture "may be read as an almost pure form of "hegemonic masculinity."' This type of culture is characterized by aggression, competition, rigid in-group=out-group distinctions, and an acute heterosexist orientation. This blatant heterosexism often takes the form of "patriarchal and misogynistic attitudes toward women" (Fielding 1994, p. 47). Martin (1989) notes that maintenance of sexist attitudes is often tied to police officers' occupational identities. Stereotypic displays of masculinity are expected and encouraged by public ideals and by other members of the police force. Socialization into police work, in combination with social isolation from the public, promotes a police "personality" and a subculture of policing. This subculture is protective of its identity and its members, who tend to share common attitudes, beliefs, and worldviews (McNamara 1999).

In addition, Bradley, Walker, and Wilkie (1986) note the strong resistance to change inherent in police culture. They regard this resistance to change as a form of pessimism; for example, "whatever we do, things will not improve, we are prisoners of forces beyond our control." All of these factors indicate that police culture and individual police officers maintain rigid attitudes about the roles and actions of men and women in society. These strict role definitions may contribute to a general police culture that is negative towards women and facilitate the continued acceptance of rape myths.

Police work is characterized by its own occupational beliefs and values that are generally shared by officers in the United States (Herbert 1997). Agents of the criminal justice system do not operate in a vacuum, of course, but are guided by laws and procedures. As members of a subculture, police officers import many values and beliefs from the broader society in which they live. For example, the conservative and masculine disposition of officers may be a reflection of the type of individuals drawn to police work (Roberg et al. 2004). These attitudes, beliefs, and norms are reinforced through communication and association with more experienced police officers (McNamara 1999). Given the masculine ideals that pervade police culture (Murrell and Lester 1979), one would expect this rigid adherence to gender roles to influence the acceptance of rape myths.

Research on female police officers suggests they are victims of harassment and discrimination. They are often sexually harassed and do not receive equal credit for their work (Daum and Johns 1994). Timmins and Hainsworth (1989) found that sexual harassment and discrimination were far more prevalent than expected among 
police officers, and that harassment is supported and carried out by supervisory officers. Martin (1989) suggested that a sexist atmosphere often causes female officers to withdraw and to fail to build interpersonal relationships necessary for mentoring and sponsorship.

Several studies suggest that police officers with a college education are more aware of social problems and are more accepting of traditionally oppressed groups (Weiner 1976). These officers are also generally more professional and ethical in their attitudes and behavior (Tyre and Braunstein 1992; Truxillo et al. 1998). Other studies indicate that police officers with higher levels of education are less authoritarian than those with less formal education (Smith et al. 1968; Smith et al. 1970).

Smith and Aamodt (1997) speculated that the benefits of a college education may not become apparent until paired with on-the-job experience, indicating that education is only one tool and should be used in conjunction with training and experience. Another study assessing the relationship between attitudes and performance found that officers with "college degrees had the most open belief systems and highest levels of job performance, indicating that collegeeducated officers were better able to adapt to the complex nature of the police role" (Roberg 1978, p. 344). These findings indicate that the overall experience of a college education may prove beneficial in broadening police officers' attitudes and improving performance, including the use of discretion.

If we couple the continuing presence of gender, views of rape and the masculine culture of policing, then it becomes necessary to assess how the culmination of these views affect how women in general, and victims of rape in particular, are assessed by police officers. Research has shown that male rape victims and prostitutes who are victims of rape are not viewed by the public as "real victims" (Mitchell et al. 1999; Miller and Schwartz 1995; Gilmartin-Zena 1988). It is also evident that the public still generally endorses rape myths, especially when characteristics of the crime fail to adhere to the "real rape" model (Johnson et al. 1997; Viki and Abrams 2002; DuMont et al. 2003). Further, we know that male police officers tend to be more accepting of rape myths than their female counterparts (Page 2007).

Rape is a traumatic and devastating crime for the victim. Police officers are likely the first contact a victim has with the criminal justice system and the only avenue for seeking justice. If $s=$ he is met with disbelief or downplaying the severity of the offense, $s=$ he may decide not to prosecute. This experience may also dissuade other victims from reporting rapes to police. Given the discretionary nature of 
police work, it is important to explore the attitudes of police officers which may affect their decision making. The current study was designed to assess police officers' attitudes toward women and rape using a quantitative measure.

\section{METHODS}

The population was identified using a snowball method. A colleague who works with a private training academy supplied the names of several Chiefs of Police and Sheriffs in two states in the Southeastern United States who were willing to participate in the study. Those individuals, in turn, supplied additional names of Chiefs of Police and Sheriffs. All referred Chiefs of Police, Sheriffs, or contact persons were contacted and assistance was requested. All police departments willing to participate were included in the population. Seven police departments and four sheriff's departments agreed to participate in the study. Four police and sheriff's departments declined, citing time constraints or the belief that few officers would be willing to participate. I later discovered that at least two of the four police departments that declined participation had launched sexual assault or domestic violence investigations against a police officer within the department.

\section{Procedures}

A census of the eleven identified police departments and sheriff's offices was conducted. These agencies were located in two states in the Southeast United States. Participants were asked to complete a survey dealing with police officers' perspectives on interpersonal violence. They were advised that their participation would contribute to the existing body of literature on the topic. Participants were told that their participation in the study was voluntary and that they could elect not to complete the survey with no career, occupational, or training repercussions. The participants were assured that all their responses would remain anonymous. I further assured departments that individual or department names would not be referenced in any written report. The officers were informed that the research staff would not have access to names of individuals, nor would any characteristics of the departments be released. Whereas this sample is not necessarily representative of police officers throughout the United States, findings will shed light on the attitudes of sworn police officers in the surveyed areas. This study represents a census in that every member of the identified population had the option of completing a survey. Those who responded to the survey represent one-third of 
the population of interest.

\section{Survey Instrument}

The survey was a combination of demographic questions and four attitudinal scales: (1) Swim, Aikin, Hall and Hunter's (1995) OldFashioned Sexism Scale (OFSS) and (2) Modern Sexism Scale (MSS); (3) a Rape Myth Acceptance Scale-Revised (RMA-R); and (4) a Victim Credibility Scale (VCS).

Swim and colleagues' (1995) OFSS and MSS were intended to reflect, respectively, the stereotyped sexist attitudes often associated with hegemonic masculinity as well as the more subtle forms of modernday sexism: for example, dismissing the persistence of sex-based discrimination. The scales were based on McConahay's (1986) Modern Racism Scale, with items altered to apply to women (that is, to measure sexism). The response set for both scales ranged from "Strongly Disagree" to "Strongly Agree" and used a five-point scale. The OFSS had a Cronbach (a) coefficient of 0.73 . The MSS had a Cronbach $(\alpha)$ coefficient of 0.77 . High scores on the scales indicated the presence of "old-fashioned" and modern sexist attitudes, respectively.

The RMA-R was adapted from Burt's (1980) rape myth acceptance scale. Her scale contained 14 items and assessed levels of endorsement of myths about rape, rapists, and victims of rape. A rape myth is a stereotyped belief about rape that places blame for the crime on the victim. Burt's scale was altered by removing items that seemed superfluous or outdated. Several items that were not legally relevant to the study of rape at the time of Burt's (1980) study were added to the scale. For instance, the item "Any man can be raped" was included in the revised scale. When Burt created her RMA, rape was defined in criminal law as a crime against a woman. Rape law reforms led to the adoption of gender-neutral language, making it legally possible for a male to be raped. Several original items that were double-barreled were made into separate items or shortened. For example, the item "When women go around braless or wearing short skirts or tight tops, they are just asking for trouble" was shortened to "Women who dress provocatively are inviting sex."

The Rape Myth Acceptance Scale-Revised (RMA-R) consists of ten items. The response set for the scale varied from "Strongly Disagree" to "Strongly Agree" and used a five-point scale. High scores on the RMA-R indicate endorsement of rape myths. The RMA-R had a Cronbach ( $\alpha$ ) coefficient of 0.75 . 
The VCS was designed to measure how believable a certain victim would be to individual police officers. For instance, would an alleged victim be more believable if $\mathrm{s}=$ he was a teenager or an elderly person? The scale serves as a more specific measure of rape myth acceptance. Whereas the RMA-R asks about general attitudes toward rape, the VCS asks how believable rape victims are who have varying characteristics. The scale used a five-point scale ranging from "Very Unlikely" to "Very Likely." The VCS had a Cronbach ( $\alpha$ ) coefficient of 0.81 .

\section{RESULTS}

The study had a $30.7 \%$ response rate, meaning that data were available for approximately $30 \%$ of the identified population. A total of 2,898 survey packets were distributed to the population and 891 completed surveys were returned.

Eighty percent (716) of respondents were male and $17 \%(150)$ were female. Three percent (27) of respondents chose not to identify their gender. Sixty-four percent (571) of respondents identified their race as Non-Hispanic or White, $24 \%$ (213) identified themselves as African American, one percent (10) as Asian American or Pacific Islander, two percent (18) as Native American, and one percent (8) as Latino $=a$ or Hispanic. Three percent (27) classified their race as Other and five percent (44) chose not to identify their race. Nationally, local law enforcement personnel are comprised of $11 \%$ female, $12 \%$ African American, nine percent Hispanic, and three percent who classify their race as Other (U.S. Department of Justice 2006).

In terms of educational attainment, eight percent of respondents (78) held a high school diploma or GED. Forty-one percent (366) had attended some level of college, but had not obtained a degree. Fifteen percent (128) earned an Associate's degree and 29\% percent (262) earned a Bachelor's degree. Three percent (23) of respondents earned a Master's degree and three percent (29) chose not to disclose their highest level of educational attainment. The respondents ranged in age from 22 to 67 years, with the mean age being 37 .

\section{Item Analysis}

Overall, the average responses on the attitudes toward women scales show that police officers endorse some sexist attitudes and reject others. Likewise, the average response on the RMA-R indicates that 
while some rape myths are accepted, others are rejected. Table 1

Table 1. Police officers' attitudes toward women and rape: Descriptive statistics

\begin{tabular}{lcccccc}
\hline Variables & N & Mean & Stand ard deviation & Theoretical range & Actual range & $\boldsymbol{\alpha}$ \\
\hline OFSS & 873 & 10.66 & 3.431 & $5-25$ & $5-25$ & 0.73 \\
MSS & 867 & 22.11 & 4.873 & $8-40$ & $8-40$ & 0.77 \\
RMA-R & 869 & 21.83 & 5.472 & $10-50$ & $10-50$ & 0.75 \\
VCS & 866 & 18.48 & 4.690 & $8-40$ & $8-40$ & 0.81 \\
Education $^{2}$ & 862 & 2.75 & 1.070 & $1-6$ & $1-5$ & \\
\hline
\end{tabular}

Note. "Education: $1=$ High School or GED, $2=$ Some College, No Degree, $3=$ Associate's Degree, $4=$ Bachelor's Degree, $5=$ Master's Degree.

shows the mean, standard deviation and possible range of scores for the OFSS, MSS, RMA-R, and VCS.

In general, police officers did not endorse the blatantly sexist attitudes measured by the OFSS (see Table 2). A sizable minority of officers chose not to specify an opinion one way or the other, opting instead to choose "Neither Disagree or Agree." However, $45 \%$ disagreed and $29 \%$ strongly disagreed that they would be equally comfortable having a male or female boss. This item alone may have contributed to an overall sexist orientation.

As with the OFSS, a sizable minority chose not to provide opinions in agreement or disagreement with items on the MSS (see Table 3). There were also some discrepancies in the opinions. While the majority either strongly disagreed (19\%) or disagreed (41\%) with the statement "discrimination against women is no longer a problem in the U.S.," a sizable minority of officers strongly agreed $(8 \%)$ or agreed (31\%) "women often miss out on good jobs due to sexual discrimination."

Table 2. Item percentages for the Old-Fashioned Sexism Scale $(\mathrm{N}=873)$

\begin{tabular}{lccccc}
\hline Item & SD & D & NDA & A & SA \\
\hline $\begin{array}{l}\text { Women are generally not as smart as men. } \\
\text { I would be equally comfortable having a female or male boss. }\end{array}$ & 36.1 & 29.6 & 25.6 & 4.0 & 2.9 \\
$\begin{array}{l}\text { It is more important to encourage boys to participate in } \\
\text { athletics than to encourage girls. }\end{array}$ & 28.1 & 36.1 & 23.7 & 7.5 & 2.9 \\
$\begin{array}{l}\text { Women are just as capable of thinking logically as men. } \\
\begin{array}{l}\text { When both parents are employed and their child gets sick } \\
\text { at school, the school should call the mother rather }\end{array} \\
\begin{array}{l}\text { than the father. } \\
\hline\end{array}\end{array}$ & 46.4 & 32.2 & 12.6 & 4.4 & 2.7 \\
\end{tabular}

Note, $\mathrm{SD}=$ Strongly Disagree, $\mathrm{D}=$ Disagree, $\mathrm{NDA}=$ Neither Disagree or Agree, $\mathrm{A}=$ Agree, $\mathrm{SA}=$ Strongly Agree. 
Table 3. Item percentages for the Modern Sexism Scale $(\mathrm{N}=867)$

\begin{tabular}{|c|c|c|c|c|c|}
\hline Item & SD & D & NDA & A & SA \\
\hline $\begin{array}{l}\text { Discrimination against women is no longer a problem in } \\
\text { the U.S. }\end{array}$ & 19.2 & 40.7 & 25.5 & 9.4 & 3.4 \\
\hline $\begin{array}{l}\text { Women often miss out on good jobs due to sexual } \\
\text { discrimination. }\end{array}$ & 6.2 & 16.9 & 36.0 & 31.2 & 8.0 \\
\hline It is rare to see women treated in a sexist manner on TV. & 21.0 & 43.5 & 24.9 & 6.4 & 2.2 \\
\hline Husbands and wives have equal status in our society. & 10.5 & 31.4 & 27.5 & 23.6 & 4.9 \\
\hline $\begin{array}{l}\text { Society has reached the point where women and men have } \\
\text { equal opportunities for achievement. }\end{array}$ & 7.2 & 30.2 & 26.5 & 29.6 & 4.7 \\
\hline It is easy to understand the anger of women's groups in the US. & 8.3 & 22.4 & 40.3 & 23.0 & 4.2 \\
\hline $\begin{array}{l}\text { It is easy to understand why women's groups are still concerned } \\
\text { about societal limitations of women's oppor tunities. }\end{array}$ & 5.7 & 15.2 & 37.3 & 34.6 & 5.6 \\
\hline $\begin{array}{l}\text { Over the past few years, the gover nment and news media have } \\
\text { been showing more concern about the treatment of women } \\
\text { that is warranted by women's actual experiences. }\end{array}$ & 3.0 & 19.1 & 48.0 & 23.8 & 4.2 \\
\hline
\end{tabular}

Note. $\mathrm{SD}=$ Strongly Disagree, $\mathrm{D}=$ Disagree, $\mathrm{NDA}=$ Neither Disagree or Agree, $\mathrm{A}=$ Agree, $\mathrm{SA}=$ Sirongly Agree.

While police officers generally see discrimination against women as something that occurred in the past, they also recognize that some forms of discrimination still exist. The high percentage of neither disagree or agree responses could be indicative of survey fatigue or not wanting to indicate their true belief. Regardless of what an individual believes, $\mathrm{s}=$ he is generally aware of how the public views a particular statement or issue.

Findings for specific RMA-R items are noteworthy. ${ }^{2}$ As shown in Table 4, the majority of police officers agreed "any woman can be raped" (93\%) and "any man can be raped" (66\%). The majority of officers also disagreed with statements that would blame the victim, such as "in the majority of rapes, the victim is promiscuous or has a bad reputation" (65\%) or "many women secretly wish to be raped" (79\%). This item analysis would indicate that police officers might be less accepting of rape myths than was found in earlier studies.

Table 5 first shows the item percentages for the VCS. ${ }^{2}$ In general, police officers were most likely to believe someone they know (87\%), a virgin (74\%), an elderly person (82\%), or a professional woman $(75 \%)$ who claimed $\mathrm{s}=$ he was raped. Forty-four percent of the officers were unlikely to believe a prostitute who claimed $\mathrm{s}=$ he was raped. 
Table 4. Item percentages for the Rape Myth Acceptance Scale-Revised $(\mathrm{N}=869)$

\begin{tabular}{lrrrrr}
\hline Item & SD & D & NDA & A & SA \\
\hline Any woman can be raped. & 2.1 & 2.4 & 1.5 & 30.6 & 62.6 \\
Any victim can resist a rapist if s/he really wants to. & 22.3 & 35.4 & 18.5 & 16.6 & 6.1 \\
Women who dress provocatively are inviting sex. & 20.3 & 33.3 & 25.4 & 15.6 & 4.5 \\
Any man can be raped. & 5.9 & 13.5 & 13.4 & 40.9 & 25.5 \\
Many women secretly wish to be raped. & 52.6 & 26.8 & 15.6 & 2.5 & 1.6 \\
A woman is responsible for preventing her own rape. & 28.4 & 35.0 & 21.5 & 11.9 & 2.0 \\
A woman that goes to the home of a man on their first date & 32.7 & 43.8 & 16.6 & 4.4 & 1.6 \\
$\quad$ implies she is willing to have sex. & & & & & \\
$\begin{array}{l}\text { Women falsely report rape to call attention to themsclves. } \\
\text { In the majority of rapes, the victim is promiscuous }\end{array}$ & 10.0 & 30.9 & 38.4 & 17.1 & 2.6 \\
$\quad \begin{array}{l}\text { or has a bad reputation. } \\
\text { It is a woman's fault if she makes out with a guy and lets } \\
\text { things get out of hand. }\end{array}$ & 20.2 & 52.7 & 19.3 & 6.1 & 1.0 \\
\hline
\end{tabular}

Note. $\mathrm{SD}=$ Strongly Disagree, $\mathrm{D}=$ Disagree, $\mathrm{NDA}=$ Neither Disagree or Agree, $\mathrm{A}=$ Agree, $\mathrm{SA}=$ Strongly Agree.

\section{Analytic Techniques}

For the sake of testing the posited hypotheses, data for the scales were first tested for normality using the Shapiro-Wilk statistic. This statistic tests the null hypothesis that the data are normally distributed. Results showed that none of the scales were normally distributed, meaning that parametric statistics could not be used to test the four

Table 5. Item percentages for the Victim Credibility Scale $(\mathrm{N}=866)$

\begin{tabular}{lrrrrr}
\hline Item & VU & U & NUL & L & VL \\
\hline A person comes to you and claims a rape has occurred. & & & & & \\
$\quad$ How likely would you be to belleve the statement & & & & & \\
$\quad$ if the person was: & 1.0 & 1.2 & 9.5 & 42.3 & 44.7 \\
Someone you know. & 1.3 & 3.3 & 19.9 & 48.0 & 25.9 \\
A virg in. & 1.0 & 3.3 & 26.2 & 52.7 & 15.3 \\
A teenager. & 0.9 & 2.1 & 12.9 & 43.5 & 38.4 \\
An elderly person. & 14.5 & 29.6 & 29.3 & 19.1 & 5.8 \\
A prostitute. & 4.3 & 16.7 & 29.7 & 34.9 & 12.7 \\
A man. & 1.0 & 1.2 & 20.9 & 58.1 & 17.3 \\
A professional woman. & 4.8 & 14.1 & 37.0 & 33.3 & 9.2 \\
A married woman accusing her husband. & & & & & \\
\hline
\end{tabular}

Note. $\mathrm{VU}=$ Very Unaked, $\mathrm{U}=$ Unakely, $\mathrm{NUL}=$ Neither Unlikely nor Likely, $\mathrm{L}=$ Likeh, $\mathrm{VL}=$ Very Likeb.

primary hypotheses. Given the construction of the response scalesranging from "Strongly Disagree" to "Strongly Agree" with "Neither Disagree or Agree" as the midpoint-one would not expect the data to be normally distributed. Measures of attitudes toward women and attitudes toward rape are topics that elicit definitive opinions 
in one direction or another. They are not neutral in nature; therefore, one would expect data to be loaded on either end of the response scale.

The Spearman Rank Correlation, the Kruskal-Wallis test, and the Mann-Whitney test were used to test the hypotheses. These nonparametric statistics do not make assumptions about the distribution of data and are also less sensitive to uneven groupings of data. The Spearman Rank Correlation tests the relationship between variables using the rank order of frequencies of observations rather than the recorded value. Such ordering makes the statistic less vulnerable to asymmetrical distributions or outliers. The Kruskal-Wallis test is the nonparametric equivalent of the one-way analysis of variance for independent samples. It is calculated based on the sums of the ranks of combined groups and tests the null hypothesis that there are no significant differences between the means of the groups being tested. If a significant difference is found using the Kruskal-Wallis, the Mann-Whitney test can then be used to make comparisons between two specific groups. The latter is the equivalent of the independent samples t-test. The Mann-Whitney is computed by ranking the combined scores of both groups from smallest to largest. It tests the null hypothesis that group means are not significantly different.

\section{Old-Fashioned and Modern Sexism}

Whereas some research has been conducted on the relationship between educational attainment and public or lay attitudes toward women (Burt 1980; Glick et al. 2002), we have little knowledge of the relationship between educational attainment and police officers' attitudes toward women. Studies have shown that college-educated police officers are more attuned to social problems (e.g., Weiner 1976) than their less-educated counterparts. These social problems include gender oppression (e.g., rape). Studies of the general public have also found individuals with higher levels of education to hold more egalitarian attitudes toward women (Burt 1980).

Therefore, it was hypothesized that police officers with higher levels of educational attainment would hold more egalitarian attitudes toward women than police officers with lower levels of educational attainment. A Kruskal-Wallis test was used to determine if police officers differed by educational attainment on scores on the OFSS and the MSS. There was no significant difference observed between police officers' scores on the OFSS, regardless of their level of educational attainment $\left(X^{2}=8.109, p=.088\right)$. The OFSS measures blatantly sexist attitudes, which are generally regarded today 
as unacceptable.

However, there was a significant difference between police officers' level of educational attainment and their scores on the MSS $\left(X^{2}=16.036, p<.05\right)$. The Mann-Whitney test was used to compare levels of educational attainment. Police officers with a high school diploma or GED significantly differed on scores of the MSS than did police officers with a Master's degree $(U=405, p<.001)$. Specifically, police officers with a high school diploma or GED scored significantly higher on the MSS than did police officers with a Master's degree. Further, police officers with some college education scored significantly higher than did those with a Master's degree $(U=2393.5, p=.001)$. Officers with an Associate's degree also scored significantly higher on the MSS than did those with a Master's degree $(U=740.5, p<.001)$. Police officers with a Bachelor's degree differed significantly on the MSS than did those with a Master's degree $(U=1690, p<.001)$, such that respondents with a Bachelor's degree scored significantly higher. The Mann-Whitney test was also computed to test for significant differences between other levels of educational attainment and scores on the MSS (i.e., some college education compared to Associate's degree and Associate's degree compared to Bachelor's degree). None of these comparisons yielded statistically significant differences.

\section{Relationship Between Attitudes Toward Women and Rape}

It was also hypothesized that scores on the RMA-R would be positively correlated with scores on the OFSS and the MSS. Police officers who adopt stereotypical attitudes about social and sexual roles for men and women will also be more likely to accept rape myths, which derive from traditional gender schemas. A Spearman Rank Correlation was calculated for the scales. The RMA-R was positively, significantly correlated with the OFSS (Spearman $=.406$, $\mathrm{p}<.001$ ) and the MSS (Spearman $=.349, \mathrm{p}<.001$ ). In other words, police officers who accept more rape myths are also likely to score higher on measures of both old-fashioned and modern sexism.

\section{Attitudes Toward Rape}

As stated previously, research has found that police officers with higher levels of education are more familiar with social problems. Burt (1980) also found that individuals with higher levels of educational attainment accepted fewer rape myths than individuals with 
lower levels of educational attainment. Therefore, it was hypothesized that police officers with higher levels of educational attainment would accept fewer rape myths. The Kruskal-Wallis test was run to see if there were differences between levels of educational attainment and scores on the RMA-R. There was a significant difference between levels of educational attainment and RMA-R scores $\left(X^{2}=16.507\right.$, $\mathrm{p}<.05)$.

The Mann-Whitney test was used to determine whether certain levels of educational attainment were significantly different from other levels for scores on the RMA-R. Police officers who had a high school diploma or GED were significantly different from those who had an Associate's degree $(U=3822, p<.05)$, such that officers with a high school diploma or GED scored significantly higher on the RMA-R than did officers with an Associate's degree. Police officers with a high school diploma or GED also scored significantly higher than did those who had a Bachelor's degree $(U=7056, p=.001)$. Finally, police officers with a high school diploma or GED differed significantly from those with a Master's degree $(U=485, p=.001)$ : specifically, officers with a high school diploma or GED scored significantly higher on the RMA-R than did those with a Master's degree. The Mann-Whitney test was also computed to test for significant differences between other levels of educational attainment and scores on the MSS (i.e., some college education versus Associate's degree and Associate's degree versus Bachelor's degree). None of these comparisons yielded statistically significant differences.

\section{Victim Credibility}

The VCS provided a more specific measure of rape myth acceptance than the RMA-R. While police officers may view the crime of rape as a significant and awful crime, they may still discount the experiences of specific victims. For instance, the vast majority (94\%) of police officers agreed on the RMA-R that any woman can be raped, yet when asked about victim credibility on the VCS, $19 \%$ were unlikely to believe a married woman who claimed she was raped by her husband and $44 \%$ were unlikely to believe a prostitute who claimed $s=$ he was raped. Only five percent of police officers were unlikely to believe a virgin and just two percent were unlikely to believe a professional woman who claimed she was raped. This contrasting information suggests that it still does, in fact, matter what "kind" of woman claims she was raped. Likewise, $67 \%$ of respondents agreed that any man could be raped. However, when asked how likely they would be to believe a man who claimed he was raped; $48 \%$ of respondents indicated they would believe the person. 


\section{DISCUSSION}

As with any research, mine was prone to certain limitations. For example, participants were aware that I am a woman (as my name and contact information were listed on the survey) and a strong social desirability element may have persisted given the nature of the topic. Rape is a difficult and sensitive topic to discuss, especially with individuals in the context of their work environment. Police officers operate in a closed environment, as do members of any organization (McNamara 1999). They may have felt an obligation to portray that organization in a favorable light. This sense of obligation, along with wanting to portray themselves individually in a positive way, may have influenced their responses.

A second limitation of the measures is less amenable to remedy. The study used quantitative scales to gather information about attitudes. These scales may overlook subtle nuances that a qualitative interview would capture. After all, as Gerring (2001) notes, scales are limited in scope and application to social life. Finally, and related to the problems of survey research, these data are cross-sectional. It is unknown whether people who seek advanced education are already more progressive in their attitudes toward women and rape. If so, then the apparent effect of education on attitudes toward women and rape is negated by their already progressive ideologies. Despite these limitations, the measures used reveal something about police officers' attitudes toward women and rape since the institution of reforms.

\section{CONCLUSION}

Research has established that the public holds attitudes toward women and rape based on traditional gender schemas (Benokraitis and Feagin 1986; Rowe 1990; Swim et al. 1995). The purpose of this research was to determine if police officers also hold these attitudes and to examine whether educational attainment might influence their attitudes.

The findings of this research concur with most prior research on police officers and attitudes toward rape (Galton 1975; Field 1978; LaFree 1989; Campbell 1995; Campbell and Johnson 1997; FeldmanSummers and Palmer 1980; Brown and King 1998). Police officers endorse some rape myths. However, the level of endorsement differs with educational attainment. Officers with higher levels of educational attainment were less likely to endorse rape myths, while police officers with lower levels of educational attainment were 
more accepting of rape myths.

Generally speaking, the police officers studied did not hold "old-fashioned" sexist attitudes toward women, regardless of their educational attainment. This finding was not completely unexpected as these blatant statements are generally unacceptable in the contemporary Western mainstream. Openly sexist ideas are no longer publicly endorsed (McConahay 1986).

A sizable minority of police officers studied did hold "modern" sexist attitudes toward women. Modern sexism is a subtle form of sexism, such as denying that discrimination continues to be prevalent. Police officers differed significantly on scores of the MSS according to their educational attainment. Police officers with the highest levels of educational attainment were more egalitarian in their attitudes toward women than were officers with lower levels of education.

Overall, police officers tend to view the crime of rape as a serious one. However, research indicates that while they view rape as significant, they are more likely to discredit victims that do not adhere to stereotyped victim characteristics. Many of the characteristics that comprise the real victim fit within the traditional framework of gendered expectations as they relate to sexuality. It is possible that adhering to sexist ideologies, whether modern or old-fashioned, would negatively affect how particular rape victims are seen by police officers and whether their cases are deemed credible.

\section{Footnotes}

${ }^{1}$ Reports of rape were deemed false when the victim admitted s/he fabricated the allegation or when proof of fabrication was obtained.

${ }^{2}$ These results were published in an earlier article by Page (2007).

\section{REFERENCES}

Bart, P. B. 1979. "Rape as a Paradigm of Sexism in Society: Victimization and its Discontents.” Women's Studies International Quarterly 2:347-357.

Beall, A. E. 1993. "A Social Constructionist View of Gender." Pp. 127-147 in The Psychology of Gender, edited by A. E. Beall and R. J. Sternberg. New York: Guilford Press. 
Bem, S. L. 1981. "Gender Schema Theory: A Cognitive Account of Sex Typing." Psychological Review 88(4):354-364.

Benokraitis, N. V. and J. R. Feagin. 1986. Modern Sexism. Englewood Cliffs, NJ: Prentice Hall.

Biernat, M. and Wortman, C. B. 1991. "Sharing of Home Responsibilities Between Professionally Employed Women and their Husbands." Journal of Personality and Social Psychology 60:844-860.

Bonney, R. 1985. Bureau of Crime Statistics and Research Crimes: Sexual Assault Amendment Act. Sydney: Attorney General's Department.

Bradley, D., N. Walker, and R. Wilkie. 1986. Managing the Police: Law, Organisation and Democracy. Brighton, UK: Wheatsheaf.

Brown, J. and King, J. 1998. "Gender Differences in Police Officers' Attitudes towards Rape: Results of an Exploratory Study." Psychology, Crime, and Law 4:265-279.

Burt, M. R. 1980. "Cultural Myths and Support for Rape." Journal of Personality and Social Psychology 38:217-230.

Cairney, K. F. 1995. "Addressing Acquaintance Rape: The New Direction of the Rape Law Reform Movement." St. John's Law Review 69:291-326.

Campbell, R. 1995. "The Role of Work Experience and Individual Beliefs in Police Officers' Perceptions of Date Rape: An Integration of Quantitative and Qualitative Methods." American Journal of Community Psychology 23(2): 249-277.

Campbell, R. and Johnson, C. R. 1997. "Police Officers' Perceptions of Rape: Is There Consistency between State Law and Individual Beliefs?" Journal of Interpersonal Violence 12(2):255-274.

Clay-Warner, J. and Burt, C. H. 2005. "Rape Reporting After Reforms: Have Times Really Changed?" Violence Against Women 11(2):150-176.

Connell, R. W. 1987. Gender and Power. Cambridge, UK: Polity. 1995. Masculinities. Los Angeles: University of California Press.

—. 2002. Gender (Short Introductions). Cambridge, UK: Polity Press.

Daum, J. and Johns, C. 1994. "Police Work from a Woman's Perspective." The Police Chief 61:46-69. 
Doherty, K. and Anderson, I. 1998. "Perpetuating Rape-Supportive Culture: Talking About Rape." The Psychologist 11(12):583-587.

DuMont, J., K. Miller, and T. L. Myhr. 2003. "The Role of 'Real Rape' and 'Real Victim' Stereotypes in the Police Reporting Practices of Sexually Assaulted Women." Violence Against Women 9(4):466-486.

Feldman-Summers, S. and G. C. Palmer. 1980. "Rape as Viewed by Judges, Prosecutors, and Police Officers." Criminal Justice and Behavior 7(1):19-40.

Field, H. S. 1978. "Attitudes toward Rape: A Comparative Analysis of Police, Rapists, Crisis Counselors, and Citizens." Journal of Personality and Social Psychology 36(2):156-179.

Fielding, N. 1994. "Cop Canteen Culture." Pp. 46-63 in Just Boys Doing Business? Men, Masculinities and Crime, edited by T. A. Newburn and E. A. Stanko. London: Routledge.

Fortier, L. 1975. "Women, Sex and Patriarchy." Family Planning Perspectives $7(6): 278-281$.

Galton, E. R. 1975. "Police Processing of Rape Complaints: A Case Study." American Journal of Criminal Law 4(1):15-30.

Gerring, J. 2001. Social Science Methodology: A Criterial Framework. New York: Cambridge University Press.

Gilmartin-Zena, P. 1988. "Gender Differences in Students' Attitudes Toward Rape.” Sociological Focus 21(4):279-292.

Glick, P., M. Lameiras, and Y. R. Castro. 2002. "Education and Catholic Religiosity as Predictors of Hostile and Benevolent Sexism Toward Women and Men." Sex Roles 47(9-10):433-441.

Herbert, S. 1997. Policing Space: Territoriality and the Los Angeles Police Department. Minneapolis: University of Minnesota Press.

Holdaway, S. 1983. Inside the British Police: A Force atWork. Oxford: Basil Blackwell. Johnson, A. G. 1997. The Gender Knot: Unraveling Our Patriarchal Legacy. Philadelphia: Temple University Press.

Johnson, B. E., D. L. Kuck, and P. R. Schander. 1997. "Rape Myth Acceptance and Sociodemographic Characteristics: A Multidimensional Analysis." Sex Roles 
36(11=12):693-707.

Jordan, J. 2001. "Worlds Apart? Women, Rape and the Police Reporting Process." British Journal of Criminology 41(4):679-706.

Kimmel, M. S. 2000. The Gendered Society. New York: Oxford University Press.

LaFree, G. D. 1989. Rape and Criminal Justice: the Social Construction of Sexual Assault. Belmont, CA: Wadsworth Publishing.

Lorber, J. 2003. "The Social Construction of Gender." Pp. 113-120 in Reconstructing Gender: A Multicultural Anthology (3rd ed.), edited by E. Disch. Boston:

McGraw-Hill, Inc.

Martin, S. 1989. "Women in Policing: The Eighties and Beyond." in Police and Policing Contemporary Issues, edited by D. Kenney. New York: Praeger.

Mayerson, S. E. and D. A. Taylor. 1987. "The Effects of Rape Myth Pornography on Women's Attitudes and the Mediating Role of Sex Role Stereotyping." Sex Roles $17(5=6): 321-338$.

McConahay, J. B. 1986. "Modern Racism, Ambivalence, and the Modern Racism Scale." Pp. 91-125 in Prejudice, Discrimination, and Racism, edited by J. F. Dovidio and S. L. Gaertner. Orlando, FL: Academic Press.

McNamara, R. P. 1999. "The Socialization of the Police." Pp. 1-12 in Police and Policing: Contemporary Issues, 2nd ed., edited by D. J. Kenney and R. P. McNamara. Westport, CT: Praeger.

Messerschmidt, J. W. 2000. Nine Lives: Adolescent Masculinities, the Body, and Violence. Boulder, CO: Westview Press.

Miller, J. and M. D. Schwartz. 1995. "Rape Myths and Violence Against Street Prostitutes."

Deviant Behavior 16:1-23.

Mitchell, D., R. Hirschman, and G. C. Nagayama Hall. 1999. "Attributions of Victim Responsibility, Pleasure and Trauma in Male Rape." The Journal of Sex Research 36(4):369-373.

Murrell, M. E. and D. Lester. 1979. "Masculinity in Police Officers." Psychological Reports 44:14.

Page, A. D. 2007. "Behind the Blue Line: Investigating Police Officers' Attitudes

Toward Rape." Journal of Police and Criminal Psychology 22(1):22-32. 
Roberg, R. 1978. "An Analysis of the Relationships Among Higher Education, Belief Systems, and Job Performance of Patrol Officers." Journal of Police Science and Administration 6:336-344.

Roberg, R., J. Crank, and J.Kuykendall. 2004. Police and Society, 2nd ed. Los Angeles, CA: Roxbury.

Rowe, M. P. 1990. "Barriers to Equality: The Power of Subtle Discrimination to Maintain Unequal Opportunity." Paper presented at the 98th Annual Convention of the American Psychological Association. Boston, MA.

Schwartz, P. and V. E. Rutter. 1998. The Gender of Sexuality: Sexual Possibilities (Gender Lens). Thousand Oaks, CA: Pine Forge Press.

Scott, M. B. and S. M. Lyman. 1968. "Accounts." American Sociological Review $33: 46-62$.

Smith, S. M. and M. G. Aamodt. 1997. "The Relationship Between Higher Education, Experience, and Police Performance." Journal of Police and Criminal Psychology 12:7-14.

Smith, A. B., B. Locke, and A. Fenster. 1970. "Authoritarianism in Policemen Who Are College Graduates and Non-College Graduates." Journal of Criminal Law, Criminology and Police Science 61:313-315.

Smith, A. B., B. Locke, and W. F. Walker. 1968. "Authoritarianism in Police College Students and Non-Police College Students." Journal of Criminal Law, Criminology, and Police Science 59:440-443.

Spears, J. W. and C. C. Spohn. 1996. "The Genuine Victim and Prosecutors' Charging Decisions in Sexual Assault Cases." American Journal of Criminal Justice 20(2):183-205.

Spohn, C. and J. Horney. 1993. "Rape Law Reform and the Effect of Victim Characteristics on Case Processing." Journal of Quantitative Criminology 9(4):383-409.

1996. "The Impact of Rape Law Reform on the Processing of Simple and Aggravated Rape Cases." Journal of Criminal Law and Criminology 86(3):861-872.

Stanko, E. A. 1997. "Safety Talk: Conceptualizing Women's Risk Assessment as a 'Technology of the Soul'." Theoretical Criminology 1(4):479-499.

Stroh, L. K., J. M. Brett, and A. H. Reilly. 1992. "All the Right Stuff: A Comparison of Female and Male Managers' Career Progression." Journal of Applied 
Psychology 77:251-260.

Swim, J. K., K. J. Aikin, W. S. Hall, and B. A. Hunter. 1995. "Sexism and Racism: Old-Fashioned and Modern Prejudices." Journal of Personality and Social Psychology 68(2):199-214.

Temkin, J. 1997. "Plus ca Change: Reporting Rape in the 1990s." British Journal of Criminology 37(4):507-528.

Timmins, W. M. and B. E. Hainsworth. 1989. "Attracting and Retaining Females in Law Enforcement." International Journal of Offender Therapy and Comparative Criminology 33:197-205.

Truxillo, D. M., S. R. Bennett, and M. L. Collins. 1998. College education and police job performance: A ten year study. Public Personnel Management 27(2):269-280.

Tyre, M. and S. Braunstein. 1992. "Higher Education and Ethical Policing." FBI Law Enforcement Bulletin June:6-10.

U.S. Department of Justice, Bureau of Justice Statistics. 2006. Law Enforcement Management and Administrative Statistics: Local Police Departments, 2003. Washington, DC: U.S. Department of Justice.

Viki, G. T. and D. Abrams. 2002. "But She Was Unfaithful: Benevolent Sexism and Reactions to Rape Victims Who Violate Traditional Gender Role Expectations." Sex Roles 47(5=6):289-293.

Wade, C. and C. Tavris. 1998. "The Longest War: Gender and Culture." in Questions of Gender: Perspectives and Paradoxes, edited by D. L. Anselmi and A. L. Law. Boston: McGraw-Hill, Inc.

Ward, C. 1995. Attitudes Toward Rape: Feminist and Social Psychological Perspectives.

London: Sage.

Weiner, N. 1976. "The Educated Policeman." Journal of Police Science and Administration December:450-457.

Wesely, J. K. and E. Gaarder. 2004. "The Gendered 'Nature' of the Urban Outdoors: Women Negotiating Fear of Violence." Gender \& Society 18(5):645-663.

West, C. and D. H. Zimmerman. 1987. "Doing Gender." Gender and Society 1(2):125-151. 